\title{
Emprendedores sin tierra: neoliberalismo, reforma y lucha campesina en Palmar Sur de Osa
}

Landless entrepreneurs: neoliberalism, reform and peasant struggle in Palmar Sur, Osa

\author{
María José Guillén Araya \\ Clark University \\ Worcester, Estados Unidos \\ mguillnaraya@clarku.edu
}

\begin{abstract}
RESUMEN. Este artículo es uno de los resultados de un proceso de investigación-acción con organizaciones campesinas de Palmar Sur de Osa. En él se analiza la reforma institucional que transforma el Instituto de Desarrollo Agrario en el Instituto de Desarrollo Rural y su política de dotación de tierras, privilegiando la experiencia de lucha campesina de dichas organizaciones. La aproximación neoliberal de la política se hace patente en los hallazgos de la investigación: la reforma promueve la producción de una subjetividad emprendedurista, al mismo tiempo que se consolida un proceso de desposesión en el cual las personas campesinas son separadas de la tierra. El estado regula el acceso a este medio de producción, ya no a través de la titulación, sino mediante el control de la conducta económica de los llamados "beneficiarios" de la política pública.
\end{abstract}

PALABRAS CLAVE. Neoliberalismo, estado, reforma agraria, estudios campesinos, ruralidad

ABSTRACT. This article is one of the outcomes of an action-research process with peasant organizations in Palmar Sur, Osa; privileging the experience of struggle of these organizations, I analyze the institutional transformation of the Agrarian Development Institute into 
the Rural Development Institute, and its land distribution policy. The neoliberal approach of the policy is evident in the findings of this research: the reform promotes the production of an entrepreneurial subjectivity, while consolidating a process of dispossession in which peasants are separated from the land. The state regulates the access to this means of production no longer through ceding property deeds but by controlling the economic conduct of the so-called "beneficiaries" of the public policy.

KEYWORDS. Neoliberalism, state, agrarian reform, peasant studies, rurality.

\section{INTRODUCCIÓN}

La narrativa excepcionalista de la historia costarricense enfatiza las particularidades de la formación estatal del país, al mismo tiempo que esconde una multiplicidad de procesos de abstracción, disputa, negociación, dominación y violencia política. El interés de este artículo es analizar a profundidad la transformación del Instituto de Desarrollo Agrario (IDA) en el Instituto de Desarrollo Rural (INDER) a la luz de dos dimensiones que muestran algunos de estos procesos. La primera, el cambio institucional en materia de distribución de tierras, donde específicas racionalidades políticas y su traducción en ideas y prácticas institucionales hacen emerger a un cierto tipo de sujeto: el "beneficiario" de política pública cuya definición relativamente difusa, para el caso específico del INDER, funciona constriñendo más que habilitando la libertad de acción de quien queda etiquetado como tal.

La segunda, los procesos de encuentro de las prácticas organizativas y de lucha social con los códigos y subjetividades planteadas en la política pública. El caso de estudio se ubica en la zona Sur de Costa Rica, una de las regiones del país donde el conflicto agrario es la tendencia histórica. Como una manera de des-fetichizar al estado ${ }^{1}$, mi análisis se enfocará no en la maquinaria institucional (metáfora mecanicista); sino en la confluencia de resistencias,

1 Mi decisión de usar la minúscula no es solamente gramatical, sino sobre todo teórica. Pienso en el estado como una red compleja de instituciones, actores, prácticas, procedimientos y lenguajes que, aunque polífonos y cacofónicos, se muestran bajo una apariencia coherente que suele ser fetichizada como una unidad o un objeto homogéneo: el Estado, en mayúscula, con nombre propio, como si fuera un lugar y/o una persona. 
concesiones y negociaciones sociales que configuran los procesos de gubernamentalidad neoliberal (à la Foucault) ${ }^{2}$. El énfasis estará puesto en algo tan aparentemente banal como la operativa de la política de dotación de tierras del INDER, en la que estos encuentros toman su forma. Para comprender estas dos dimensiones de la transformación del IDA en el INDER, el texto se organiza en tres secciones: Gobernanza neoliberal y Reformas institucionales, Transformaciones agrarias y Lucha por la tierra en Palmar Sur, y Transformación del IDA en el INDER; finalmente, se presentan las conclusiones.

Pero antes del análisis, una nota metodológica. El trabajo de campo constó de visitas quincenales durante dos años y medio (enero del 2017- julio del 2019) a las Fincas. El objetivo original consistía en la sistematización de la conflictividad socioambiental en la zona. Iniciamos un proceso de exploración en transectos y posteriormente de mapeo participativo sobre tenencia y uso de la tierra, que luego se extendió al mapeo de desastres socio-naturales, así como a la construcción de datos demográficos de la comunidad para la toma de decisiones de las organizaciones y reconstrucción de la memoria colectiva del proceso de lucha (Domínguez et al, 2019).

La investigación-acción nos arrojaba evidencia histórica y geográfica sobre la precariedad legal de la posesión de la tierra. No obstante, hubo un pequeño destello de esperanza, pues después de unos meses de haber iniciado el trabajo de campo, el INDER anunció que intervendría en Finca 10 y Finca 2-4. La esperanza se convirtió en confusión cuando la meta de obtener un título de propiedad se desvanecía conforme se empezaban a discernir los parámetros establecidos por la nueva ley que regulaba la dotación de tierras. En distintas aulas campesinas (un espacio de educación popular que sosteníamos aproximadamente una vez al mes para hablar sobre agroecología, leyes nacionales relativas a producción agrícola, e

2 Una perspectiva Foucaultiana no analiza el estado (o el crimen, la moral cristiana, la locura, la sexualidad...) desde sus lugares "naturales", en cambio, se basa en "puntos focales de experiencia" (Foucault, 2011, p.3) es decir, en el estudio de procesos de subjetivación a la luz de ejercicios de poder (ya sea como dispositivos de seguridad, disciplina o gubernamentalidad); es precisamente en los procesos de subjetivación donde Foucault redondea la noción de gubernamentalidad, al problematizar con la subjetividad la diada saber-poder, para continuar teorizando el poder hasta su muerte en 1984, aunque, las mayorías de las veces que encontramos citado las teorías de poder en Foucault en castellano solamente hacen referencia a su trabajo previo a 1978. 
intercambiar semillas) y en las reuniones sostenidas con representantes de las organizaciones fue que decidimos estudiar la ley del INDER a profundidad. Desde el TCU tuvimos varios talleres de estudio, que después se convertían en espacios de transmisión de información y discusión con representantes de las organizaciones. A este "tallereo", cartográfico y de estudio, le acompaña mi propia observación y revisión documental durante todo el trabajo de campo, por lo que en los siguientes apartados se encontraran citas del Atlas de la Memoria (2019) que producimos con las organizaciones, viñetas recogidas de mi observación y extractos de testimonios ${ }^{3}$. Las sistematizaciones de los talleres y reuniones, mis notas de campo y el Atlas de la Memoria constituyen las fuentes primarias de este artículo.

Esta investigación fue posible gracias al apoyo institucional del CIEP, la Escuela de Ciencias Políticas y de las compañeras y compañeros de Finca 10, Finca 9 y Finca 2-4 de Palmar Sur, así como del trabajo colectivo con el Programa Kioscos Socioambientales para la Organización Comunitaria, específicamente del proyecto coordinado por José Antonio Mora y asistido entonces por Valeria Morales. Finalmente, un agradecimiento a Cristopher Meza y Christopher Mora, comprometidos asistentes de investigación del proyecto en distintos momentos.

\section{GOBERNANZA NEOLIBERAL Y REFORMAS INSTITUCIONALES}

Según Massimo De Angelis (2005), siempre que decimos "gobernanza" estamos hablando de gobernanza neoliberal global, pues el surgimiento de esta palabra responde al auge político de esta doctrina económica. El neoliberalismo se distingue del liberalismo en que su tecnología política no tiene que ver tanto con la retrac-

3 Este artículo pretende ser un amplificador donde las voces campesinas puedan hacer eco. A la justificación teórico-analítica explicitada en el pie de página anterior, se le añade una metodológica y política del porqué analizar al estado desde las experiencias de subjetivación política de las personas campesinas: las y los funcionarios estatales han sido los informantes favoritos de la Ciencia Política, por lo tanto, ya tienen en las instituciones, los medios de comunicación, y el grueso de la producción politológica una voz bastante consolidada. Incluirles aquí no solamente limita el espacio para canalizar otros testimonios, sino que también contribuiría la desigualdad en las representaciones de lo que se considera "estatal" en la Ciencia Política. 
ción estatal, contenido específico de las prácticas estatales. En ese sentido, las reformas del Consenso de Washington tenían como principal bandera la desregulación de los mercados financieros, de bienes, servicios y provisiones estatales, la que fue operacionalizada en políticas de marco. Según Castro-Gómez (2015), estas políticas son aquellas en la que el estado no interviene sobre el mercado, sino en sus marcos; no en el juego, sino en sus reglas. En otras palabras, en el neoliberalismo el rol del estado se basa en regular la desregulación. Sin embargo, no está de más advertir que, los legados del estado benefactor persisten en las prácticas burocráticas, las culturas políticas de interacción con las instituciones, y las formas de percepción de lo público y lo privado, por lo que hacen un contrapeso a la aparentemente apabullante racionalidad neoliberal.

Es por estas razones (la diferencia y la advertencia arriba definidas) que, la penetración neoliberal en las formas, lenguajes y mañas estatales no puede verse solamente como medidas tomadas en frío desde élites estatales y económicas que están alejadas del grueso de la sociedad. Todo lo contrario, la gobernanza, entendida desde lo que Foucault (1978/2009, 1979/2008, 1983/2011) llamó gubernamentalidad, refiere a procesos sociales más amplios en los que las subjetividades se ven transformadas, convencidas o resistentes a actuar de cierta manera. Estos procesos sociales más amplios, sin embargo, suelen estar dirigidos por y hacia el estado, el cual a su vez es reproducido en discursos de verdad que se encuentran en variedad de esferas sociales.

Lo que se entiende como gubernamentalidad neoliberal suele operacionalizar como "gobernanza", en formas y lenguajes institucionales y de organismos internacionales. En materia de seguridad, territorio y población, Foucault (2009) ofrece un resumen inicial ${ }^{4}$ de los componentes de la gubernamentalidad, cuyas relaciones son mutuamente constituyentes: (a) la gubernamentalidad es un ensamblaje de instituciones, procedimientos, análisis, reflexiones, cálculos, tácticas que permiten el ejercicio de esta forma específica, pero compleja del poder; asimismo, (b) la gubernamentalidad es la tendencia, la línea de fuerza, que en Occidente ha llevado a la pre-eminencia de aquello llamado Gobierno, el cual se ha desarrollado en una serie de aparatos y saberes ${ }^{5}$; finalmente, (c) es el resul-

4 Este es un concepto que Foucault continuará desarrollando hasta su muerte en 1984.

5 Es necesario aclarar que hablamos de gobierno en sentido amplio, en el sentido 
tado de los procesos por los cuales el estado de justicia de la Edad Media se convirtió en el estado administrativo de los siglos XV y XVI, que fue gradualmente gubernamentalizado ${ }^{6}$. Por un lado, estos elementos de desarrollo institucional-administrativo; y por el otro, de saberes, relaciones de poder y procesos de subjetivación; están profundamente intrincados en la constitución de la gubernamentalidad y no pueden comprenderse de manera separada.

Desde la perspectiva de la conformación de subjetividad, la gobernanza presenta prescripciones de cómo los estados y las empresas deberían conducirse, a la vez que fomenta valores y actitudes en las personas. Los estados deben hacer todo lo posible por asegurar el correcto funcionamiento del mercado sin interferir en sus mecanismos directamente, las compañías deben de ser competitivas e innovadoras, y las personas deben invertir en sí mismas para ser percibidas por el mercado y los estados como capital social productivo. Así, la sociedad es concebida como un grupo de individuos que deben de resolver su supervivencia de manera independiente (emprendedurismo) (Foucault, 2009; Castro-Gómez, 2015).

Desde la perspectiva más económica, el marco de la gubernamentalidad neoliberal mira como cada vez más las tasas de crecimiento y acumulación se estancan o descienden, por lo que son necesarias re-estructuraciones que permitan aumentar la extracción y producción de valor. Menos pago por más horas de trabajo, sobre-oferta de mano de obra que abarata las remuneraciones, y esquemas que conllevan a la concentración de propiedad privada por encima de las funciones sociales de la misma, son algunos de las medidas y efectos del neoliberalismo (Harvey, 2008; Vela, 2018). Estos procesos subjetivos y económicos no son excluyentes, sino mutuamente constituyentes, y "se vuelven inteligibles en el estado" (Foucault, 2009, p. 239).

El marco de la gubernamentalidad neoliberal nos presta claves de análisis relevantes y pertinentes para mirar a las transformacio-

del control y comando a directo (disciplina) y a distancia (gubernamentalidad) de las conductas y los cuerpos de las poblaciones (biopolítica). Este gobierno se "solidifica" en los aparatos estatales, pero este no es el lugar exclusivo donde habita, pues el poder en la obra de Foucault tiene un carácter que es localizado (empíricamente identificable) y relacional.

6 Esto es de especial importancia para el caso de Europa Occidental, aunque tiene ecos históricos en este lado del Atlántico, resultado del proceso de colonización de las Américas. 
nes distribución de tierra agrícola por parte del estado. Con ellas queda claro que la gobernanza neoliberal no tiene que ver solo con el cambio en las políticas públicas (el lugar donde se hacen inteligibles estas tendencias), sino también con las transformaciones en los paisajes productivos, las estructuras socio-económicas y las formas de ser y estar en el territorio.

En materia de política pública, en el año 2000 la administración Rodríguez Echeverría presentó el proyecto de Ley no.13.882 para la transformación del Instituto de Desarrollo Agrario en el Instituto de Desarrollo Rural, el cual no llego a concretarse como ley de la República. Justamente en esa misma administración, se publica el documento "Las Políticas para el Sector Agropecuario Costarricen-

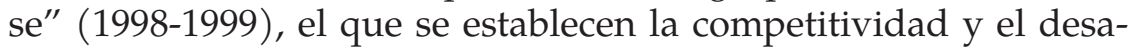
rrollo rural como los dos ejes esenciales de la política pública en esta materia (Picado \& Silva, 2002). Antes de esto, durante los años noventa, el Banco Mundial propuso una serie de elementos básicos que harían "reformas agrarias" más eficientes, al proponerse asegurar una mejor distribución de los recursos y la reducción de la pobreza rural por medio del establecimiento de mercados de arrendamiento y de venta de tierras (Deininger, 2003). Esas premisas se convirtieron en un modelo de política pública de "reforma agraria vía mercado" para países como Colombia, Brasil, Guatemala, El Salvador, Sudáfrica y las Filipinas; y más recientemente, Costa Rica, con la transformación del IDA en el INDER en 2012; aunque, como se mencionó, la intención de la reforma puede trazarse desde una década atrás. El enfoque del BM se basa en mercados descentralizados de la tierra (para evitar la corrupción y hacer más eficiente la información sobre los derechos de propiedad), una participación bien delimitada del estado, y tiene tres amplias áreas de política: 
Tabla 1. Áreas de la política pública de reformas agrarias vía mercado (MLAR, por sus siglas en inglés)

\begin{tabular}{|c|c|}
\hline $\begin{array}{c}\text { Ganar acceso } \\
\text { a la tierra }\end{array}$ & $\begin{array}{l}\text { Se trata de transacciones voluntarias entre vendedores y } \\
\text { compradores, orientadas por la demanda, es decir, solo } \\
\text { aquellos que así lo pidan serán considerados para el proceso. } \\
\text { El objetivo primordial es crear fincas familiares eficientes } \\
\text { y competitivas, para lo que los beneficiarios crean una } \\
\text { organización. En los países en que se han implementado } \\
\text { estas políticas los resultados no han sido anti-pobreza, sino } \\
\text { más bien anti-pobres: la cantidad de tierra dotada (por } \\
\text { arrendamiento o venta) ha sido mucho menor que en la } \\
\text { etapa de reformas agrarias vía estado, la calidad de la misma } \\
\text { es inferior, y los precios pagados han excedido incluso los } \\
\text { precios de mercado, se ha marginalizado del acceso a pobres } \\
\text { y personas con menor grado de educación. }\end{array}$ \\
\hline $\begin{array}{l}\text { Desarrollo de } \\
\text { la finca y el } \\
\text { beneficiario }\end{array}$ & $\begin{array}{l}\text { Aumenta el énfasis en los proyectos productivos de los } \\
\text { prospectos antes de que la tierra sea dotada, ya que los } \\
\text { proyectos funcionan con el imperativo de la viabilidad } \\
\text { económica y de costos socialmente justificables. Cada vez hay } \\
\text { menor asistencia técnica de parte de instituciones estatales, } \\
\text { ésta se ha privatizado o descentralizado. En Brasil, Guatemala, } \\
\text { las Filipinas y Sudáfrica se reportaron altos grados de } \\
\text { deserción de los proyectos productivos, y poco impacto de } \\
\text { éstos en el ingreso y el empleo. }\end{array}$ \\
\hline $\begin{array}{l}\text { Financia- } \\
\text { miento }\end{array}$ & $\begin{array}{l}\text { Hay conciencia de que los campesinos no pueden asumir el } \\
\text { costo de las transacciones de tierra e insumos en un mercado } \\
\text { abierto, por lo que debe facilitarse un subsidio en la forma de } \\
\text { un préstamo o subvención; por otra parte, los beneficiarios } \\
\text { deben asumir un parte del costo, que se transfiere del estado } \\
\text { al beneficiario en la forma de préstamo reembolsable. } \\
\text { Contrario a las expectativas, el gasto asumido por el estado ha } \\
\text { sido considerable, sobre todo por el aumento en los precios de } \\
\text { la tierra, aunque estos serán eventualmente externalizados a } \\
\text { los campesinos. }\end{array}$ \\
\hline
\end{tabular}

Fuente: Tabla de elaboración propia con base en Lahiff, Borras y Kay (2007).

La reforma del IDA al INDER mediante la Ley №9036 (2012) retoma algunos de estos elementos propuestos por el Banco Mundial (BM) para generar "desarrollo rural", los cuales se analizan más adelante para analizar los cambios en los paisajes productivos y las formas de ser y estar en el territorio se presenta el siguiente apartado. 


\section{TRANSFORMACIONES AGRARIAS Y LUCHA POR LA TIERRA EN PALMAR SUR}

Este apartado presentará algunas tendencias generales de las transformaciones agrarias en Costa Rica, específicamente en aquellas zonas mayoritariamente rurales del país, en las que el sector primario continúa siendo geográficamente predominante. Posteriormente, contextualizaré con mayor detalle estas transformaciones desde la historia de organización y movilización en Finca 2-4 y Finca 10 de Palmar Sur, con el fin de conocer el conjunto de experiencias que interactúan y forjan los procesos de cambio institucional y profundización neoliberal en el campo costarricense.

\section{La transformación del campo costarricense}

Aunque las ideas neoliberales circulaban hace más tiempo en el país (Díaz Arias, 2019), es en la década de 1980 que las coyunturas globales y locales se alinean para facilitar su implementación en los paquetes de ajuste estructural, negociación de la deuda externa y cooperación internacional. En el caso del sector agropecuario, las medidas implementadas para neoliberalizar el sector agro estaban en parte determinadas por la amplia movilización rural del proletariado agrícola y el campesinado en las dos décadas anteriores (Cartín y Román, 1991; Picado y Silva, 2002). La desregulación de los mercados agrícolas y el recorte al apoyo estatal a la producción local (Fernández, 2004) implicó la paulatina disminución desde la década de los años ochenta de la distribución de tierras por medio de la institucionalización de "asentamientos campesinos" por el Instituto de Desarrollo Agrario (IDA).

Tanto en las regiones Huetar Norte como en la Brunca, muchos de estos asentamientos campesinos eran vecinos y producto de relaciones complejas con grandes extensiones de monocultivo bananero, en los que se hacía patente la relación entre el trabajo autónomo campesino y el asalariado en el agronegocio (Guillén, 2015). El enclave bananero que había inaugurado sus extensas plantaciones, en la zona Sur desde la década de 1930, enfrentaba para inicios de la década de 1980 una serie de problemas económicos y agronómicos que debilitaban su posición como productor en el mercado mundial. Aunado a esto, las demandas de sus trabajadores por mejores condiciones de trabajo y sobre todo las luchas por un 
aumento en la remuneración llevaron a la organización de la gran huelga de 1984. El fracaso de la huelga tuvo impactos multi-escalares, ya que, marcó el debilitamiento de los sindicatos y federaciones rurales en la zona —no solo por la "guerra santa" al sindicalismo librada desde las trincheras cooperativas y del solidarismo (Wiley, 2008; Mora, 2007), sino también porque el ajuste estructural facilitó la expansión y fortalecimiento de los agronegocios-. La Compañía Bananera realmente no abandonó la zona sur después de la huelga, más bien se reconvirtió al producto más prometedor de aquel entonces: la palma aceitera.

Como es visible en el caso del banano, el sector exportador en Costa Rica ha dependido del monocultivo, pero la dinámica de los mismos ha cambiado significativamente en los últimos treinta años. Durante la mayor parte del siglo XX el café y el banano fueron las plantaciones dominantes. A partir de los años ochenta y principalmente en los noventa, la piña, la caña de azúcar y la palma aceitera fueron tomando los lugares que antes pertenecieron a los cultivos tradicionales, aun cuando el café sigue teniendo mayor extensión de tierra dedicada, sus rendimientos son inferiores por las diferencias en los sistemas productivos (INEC, 2015).

La hegemonía del monocultivo es visible en el aumento en la tendencia hacia la concentración de la tierra. Los resultados del coeficiente de Gini de la tierra crecieron de 0,79 para 1973, 0,81 para 1984 y 0,82 para 2014 (Morales y Segura, 2017). Las personas titulares de fincas pequeñas suelen ser, en muchos de los casos, "beneficiarios" de programas estatales del entonces IDA. A pesar de esto, los asentamientos formados por el IDA están muy lejos del lema de "desarrollo agrario"; según datos proporcionados por el INDER, de 1961 a 2005 esta institución (como ITCO y como IDA) había creado un total de 962 asentamientos, pero para los años noventa 230 estaban en estado de pobreza (Picado y Silva, 2002, p. 155).

Es así que, una de las críticas más comunes esgrimidas contra los asentamientos campesinos es que las personas pueden terminar vendiendo los títulos asignados, deslegitimando el sistema de redistribución. Lo cierto es que, no es de extrañar, ante las condiciones de pobreza y de dificultad para hacer prosperar las parcelas que muchas personas vendan su título como una forma de hacer frente a las presiones estructurales.

En los años ochenta, cuando ya estaba cerrada, o por cerrarse, 
la frontera agrícola del país, el tema de la escasez de la tierra surgió como contrapeso a la tendencia de institucionalización de las ocupaciones campesinas. La ley de 1984 que convirtió el ITCO en el IDA inauguró los Tribunales Agrarios, judicializando la resolución de conflictos por la tierra. Esta reforma implicó una especialización de las organizaciones campesinas, que ahora debían contar con un abogado que tradujera los lenguajes estatales y redujera el riesgo siempre latente de la criminalización (Guillén, 2018). Esta serie de transformaciones de la estructura agrícola del país no minó la organización y resistencia campesina como es evidente en el caso de Palmar Sur.

\section{Movilización social, organización y acción colectiva campesina en Palmar Sur de Osa}

Con el cierre de las plantaciones de la Compañía Bananera de Costa Rica (CBCR), después de 1984, el Pacífico Sur se vio sumido en una profunda depresión económica y psico-social, que llevo al estado costarricense a declarar zona de emergencia (Vega, 1984). Las soluciones oficiales fueron la reconversión productiva hacia la palma aceitera y el cacao, además, el fomento cooperativo. Mientras, el monocultivo palmero logró expandirse y aumentar su área a manos de la empresa PalmaTica (inicialmente parte de la CBCR) y la cooperativa Coopeagropal. Las cooperativas de producción de exempleados bananeros y las que surgieron de ocupaciones campesinas no lograron sostenibilidad financiera.

En Finca 10, después de la quiebra de la Cooperativa de Producción de Palma y Cacao de Palmar Sur (Coopalsur R.L) y del Consorcio BANASUR, a inicios de los años 2000, el entonces IDA (hoy INDER) se convirtió en el propietario legal de esas tierras. Luego del fracaso de las promesas de reactivación económica, muchas familias ex obreras bananeras o socias cooperativas entraron en procesos de recuperación de tierras, como una estrategia para garantizar la reproducción de la vida.

En Finca 10 de Palmar Sur, dichas ocupaciones se han caracterizado por su carácter casi individual, esporádico, dinámico y constante durante los últimos 20 años. Este estilo de ocupación facilitaba pasó desapercibido por los ojos del estado por mucho tiempo, por lo que las personas campesinas lograron consolidar la posesión de las parcelas por medio del trabajo y de su inclusión en el tejido 
comunitario.

Entonces, la invisibilidad de las ocupaciones para la mirada estatal se explica, por su relación de exterioridad con respecto a los grandes monocultivos de palma aceitera, como por su forma de producir: el auto-abastecimiento. Asimismo, los testimonios compartidos por los campesinos y campesinas constatan la constante movilidad, dinamismo y transformación de las parcelas, lo que dificultaba la legibilidad de parte de las autoridades: donde había una champa o rancho, en unos meses podía haber una milpa, que después de una temporada de lluvias podría convertirse en un platanar más resistente a los embates de la fuerza del agua, o una parcela podía dejar de ser de una madre y pasar a la administración de dos hijos... Y, aunque internamente cambiaban, esos terrenos verdes parecían ser lo mismo para la mirada externa.

En palabras de Massimo De Angelis, las ocupaciones habitaban el reino de lo invisible, y dejaron de pasar desapercibidas cuando se convirtieron en la "base para el rechazo, la rebelión y el éxodo" (2007, p. 61). Cuando de la invisibilidad estratégica se pasó al rechazo activo de las formas hegemónicas de producir y ser en el territorio es que estás ocupaciones se visibilizaron, se configuraron como obstáculo a la expansión del capital; pues, para la mirada estatal las ocupaciones se convirtieron en un límite geográfico y social que debía superarse (Mezzadra, 2014), para lo que se despliegan tácticas específicas. El Decreto Ejecutivo No. 36226-MOPT denominado "Declaratoria de Interés Público de las acciones para determinar la ubicación y construir un aeropuerto internacional en la zona sur de Costa Rica" fue emitido en el 2010 por la administración Chinchilla Miranda (2010-2014). Es él se determinaba la construcción de un megaproyecto de infraestructura en los terrenos correspondientes a: Finca 8, Finca 9, Finca 10 y Finca 11, sin consideración alguna de sus habitantes ni de los ecosistemas y sitios arqueológicos allí presentes. Esta declaratoria desató un proceso de organización comunitaria que no solamente denunció el objetivo de convertir a la localidad en una pista de aterrizaje gigante al servicio de la industria turística, sino que también colocó sobre la mesa el problema de la tenencia y uso de la tierra. Es en esta coyuntura que las y los campesinos de Finca 10 y Finca 9 empiezan a reclamar un título de propiedad que reconozca su trabajo en esas tierras, las que después de la catástrofe cooperativa auspiciada por el estado habían sido objeto de la indiferencia del IDA — propietario 
oficial de Finca 10 - y del Instituto de Fomento Cooperativo (INFOCOOP) - propietario de Finca 9-.

Desde el 2011 y hasta el 2018, la visibilidad que daba esta resistencia activa implicó una constante tensión con representantes gubernamentales locales y nacionales en los sectores agrícola, ambiental, aviación civil, servicios básicos, entre otros. En esos siete años, el abanico de movilizaciones y demandas campesinas tuvo como eje principal el acceso a un título de propiedad. La denuncia de la falta de caminos pavimentados y agua potable, debido a la contaminación bananera, así como la defensa del territorio contra los megaproyectos de infraestructura y la expansión de monocultivo, tenía sentido siempre que el estado pudiera proveer el aseguramiento legal con la base material de la cultura y la producción campesina, en tanto fuente de trabajo como estilo de vida (Ferlini, 2012).

Paralelamente a la amenaza de la construcción del aeropuerto sobre Finca 9 y 10, en Finca 2-4 (o "Finca Chánguena") se organizó un proceso de ocupación de tierras con un estilo de movilización distinto al de Finca 10. Aun así, ambos procesos comparten el pasado bananero y el subsecuente fracaso de las empresas cooperativas fomentadas por el estado y diseñadas en gran medida por la CBCR (Clare, 2011). El objetivo común de lucha por la tierra de Chánguena Por Siempre (comité de tierras de Finca 2-4) y Organización Lucha Campesina por Nuestras Tierras del Sur (comité de tierras de Finca 9 y 10) implicó una alianza estratégica, aunque formas muy distintas de acción colectiva.

La ocupación de tierras en Finca 10 se dio en distintos momentos. La llegada de las personas a los cables no fue concertada, sino un proceso paulatino, esporádico y desarticulado en la fase inicial de ocupación. Sin embargo, los esfuerzos individuales resultaban insuficientes para el sostenimiento de las parcelas, la formación de una organización se planteó del interés compartido por las tierras y de la necesidad de regularización del estatus legal de la tenencia. Los retos de la acción y la toma de decisiones colectivas se hicieron presentes, y con ellas cambios en la subjetividad:

"Ya cuando el INDER cayó aquí, ya esto estaba agarrado por la gente, los campesinos y todo mundo, ya estaba poblado todo eso, se vino sacando la gente, pero la gente no salió (...). Uno como es humano y es egoísta decía 'esos hijueputas precaristas metidos 
ahí', pero todos somos precaristas, ninguno tenemos nada. Tanto ellos como nosotros, no tenemos nada. Ya se fue hablando con la gente, viendo que tenían necesidades, que en verdad trabajan, porque yo ahorita digo que, si alguien está ahí y no hace nada, yo no lo defiendo, porque la tierra es de quien la trabaja" (Señora S, comunicación personal, mayo del 2017).

EstetestimoniovisibilizaelpapelquetomaelINDER(antesIDA)como dueño de las tierras de Finca 10. La eventual intervención institucional se presenta siempre ajo la amenaza de que eventualmente se construirá un aeropuerto internacional sobre Finca 8, 9 y 10, según el Atlas de la Memoria:

Más tarde llegó la amenaza del proyecto de Aviación Civil, que planeaba construir un mega-aeropuerto en Palmar Sur, en cuyos planes se visualizaban estas tierras como inhabitadas y carentes de producción. Por lo que tuvimos que organizarnos como Organización de Lucha Campesina por Nuestras Tierras del Sur para demostrar que aquí vive y trabaja una cantidad importante de personas (Domínguez et al, 2019, pág. 51).

Las parcelas se volvieron un espacio de toma de decisiones que, aunque no estaba liberado de problemas y desigualdades, representaba una opción para proyectar desde el presente un futuro otro. Los patios que antes estaban controlados por la Compañía Bananera eran re-apropiados para criar gallinas, experimentar con distintas formas de compostaje, crear huertas e intercambiar semillas; las ocupaciones revitalizaban el espacio que, si bien conservaba la forma rectangular del cable, ahora sostenía relaciones sociales diferentes.

En el 2011, con la amenaza de la construcción del aeropuerto, las acciones colectivas se vuelcan a visibilizar el hecho de que hay personas habitando las tierras destinadas al proyecto de infraestructura. Se realizó una marcha regional en alianza con pueblos indígenas y otras organizaciones sociales que también tenían entre sus demandas la cancelación del Proyecto Hidroeléctrico El Diquis. Además, se estrenó el documental "Botas con Machete" de Ferlini (2012) sobre la lucha de Fincas. Y, activistas ecologistas y académicos se unieron a la lucha con más argumentos en oposición al proyecto, el cual termina siendo archivado en 2014 (Domínguez et al, 2019). A las presiones sociales producto de la movilización, 
se le sumó la declaratoria de la UNESCO que establece a las esferas de piedra precolombinas como patrimonio de la humanidad en 2014. Es en este momento que el proyecto del aeropuerto empezó a estancarse hasta quedar desfinanciado y archivado en la Secretaría Técnica Nacional Ambiental. Sin proyecto de aeropuerto en el horizonte cercano, las familias continuaron presionando por la tierra y en junio de 2017. Así, el INDER anuncia que iniciará un proceso de dotación, lo que reaviva las esperanzas de la organización campesina desgastada por luchas sociales anteriores. Si bien la detención del proyecto fue interpretada como una victoria, las personas de Fincas quedaron en una especie de zozobra con respecto al destino de las tierras y de su relación legal con ellas.

La presencia del INDER es más clara en este periodo, pero el fantasma del aeropuerto sigue merodeando como una condicionante de la relación con las instituciones del estado. Los funcionarios estatales disciplinan a las organizaciones por medio de promesas de intervención favorables, siempre restringidas a que el gobierno no decida revivir el proyecto de aeropuerto. Las promesas son a la vez amenazas: si no se hace lo indicado, o incluso si se hace lo indicado, pero "Aviación Civil" reabre el proyecto, todo se puede desvanecer,

"Ellos lo que dicen es que el aeropuerto no va, pero, a la vez sí, no va, y por no ir, nos toca trabajar, trabajar un proyecto, pero, restringido a que el aeropuerto está y que en cualquier momento cualquiera lo puede activar" (Señora G, comunicación personal, mayo, 2019).

El caso de Finca Chánguena o Finca 2-4 es distinto en cuanto a las formas de acción colectiva, aunque la institucionalización del conflicto guarda muchas similitudes con el de Finca 10. La ocupación de las parcelas ocurre de manera concertada y colectiva, cuando cerca de 80 familias ingresan a los terrenos en 2014. El 23 de mayo de 2014, 35 familias ingresan a Finca Chánguena, la cual había sido parte de Coopalca del Sur, cooperativa bananera que luego pasó a ser administrada por el empresario Oscar Echeverría Heigol, pero que quebró a inicios del siglo XXI (Domínguez et al, 2019). Dos días después del primer ingreso de las personas campesinas, se dio el primer desalojo, aunque al día siguiente se dio un reingreso. El número de familias aumentó, entonces, reconociéndose dos grupos: "los Valerios" que fueron las primeras 35 familias que provenían de Palmar y de Ciudad Cortés, y "los de Isaac" que venían de distintos lugares y eran un número mayor (Señora P, comunicación 
personal, mayo, 2017).

La nomenclatura de los grupos se corresponde con el reconocimiento a sus "dirigentes", los que a su vez seguían la autoridad de otros dos hombres de apellidos Villalobos y Canales, quienes se volvieron las principales caras públicas del conflicto de Chánguena y Térraba, (Finca 3 es también conocida como Térraba ). La participación mayoritariamente masculina y las formas de los liderazgos verticales eran una continuidad con el modelo de organización heredado de las bananeras y las cooperativas. Sin embargo, tanto en Finca 2-4 como en Finca 10, las mujeres cada vez estaban más involucradas:

“¿Por qué solo hombres hay en la mesa si también habemos [sic] mujeres? Y algunas queremos luchar y enseñar que las mujeres también valemos, que, aunque seamos amas de casa, también trabajamos (...) yo tengo 3 oficios: ama de casa, agricultora y líder como mujer" (Señora P, comunicación personal, mayo, 2017).

La organización de Finca 2-4 se caracterizaba por la verticalidad política y la forma de acción colectiva masiva. Esta forma más tradicional de organización hizo uso de estrategias más disruptivas en el espacio público y en los medios de comunicación, cuyo impacto fue la principal táctica de negociación con el gobierno. Después de un año, entre movilizaciones callejeras, visitas a medios de comunicación y amenazas de desalojos, las personas campesinas deciden tomar el puente sobre el río Térraba, uno de los principales pasos de personas y mercancías desde la frontera Sur del país (Domínguez et al, 2019). El puente estuvo ocupado diecisiete días por las y los campesinos, así como por otros grupos solidarios a la causa, la acción consistía en un campamento que mantenía el bloqueo de la calle por medio de acciones de cuido, realizadas principalmente por las mujeres: preparación de alimentos, atención a las y los niños, turnos para velar durante la noche, etc.

Esa acción colectiva contó con el apoyo de otras organizaciones sociales alrededor del país, y sufrió represión policial (Pomareda, 2016). La toma del puente se convirtió en un momento emblemático de la lucha de Chánguena, y el inicio de una serie de encuentros y desencuentros que llevaron a la declaratoria de conflicto agrario por el INDER, y por ende el inicio de su intervención, la cual estrena la nueva reforma de dotación de tierras. 


\section{DEL IDA AL INDER O DE CAMPESINOS A EMPRENDEDORES}

El paradigma de reformas agrarias vía mercado promovido por el Banco Mundial no fue la única variable que determinó la transformación del IDA en el INDER. Internamente, también se cuestionaba el estado del "desarrollo" de las parcelas, por lo que desde los años noventa se venían justificando las reformas institucionales dentro del IDA y el Ministerio de Agricultura y Ganadería tendientes a promover la competitividad y la rentabilidad de la producción agropecuaria, reduciendo de esta manera los marcos de la función social de la tierra y, por ende, limitando las posibilidades de acceso.

En el año 2012 entra en vigencia la Ley N 9036, Transformación del Instituto De Desarrollo Agrario (IDA) en el Instituto De Desarrollo Rural (INDER). El tono de la reforma invisibiliza la seguridad jurídica que daba propiedad de la tierra al campesinado; en cambio, promueve arriendos y una conceptualización empresarial de la agricultura (Llaguno y Picado, 2011). La palabra "campesino" desaparece del lenguaje estatal y se asume un tono modernizante ligado a la nueva ruralidad (Kay, 2007, 2015). El IDA, que a su vez era una transformación del Instituto de Tierras y Colonización (ITCO), buscaba reconocer la propiedad rural, pero con el fin de aumentar la productividad (Ley $\mathrm{N}^{\circ} 6735$, art. 3, 1984), por lo que cada vez más se destinaba presupuesto para asesoría técnica ligada a productos de exportación y vinculación con transnacionales (Martínez y Morales, 2012). Con la implementación del Plan Nacional de Reforma del Sector Agropecuario, en lugar de la generar nuevos asentamientos campesinos, se buscaba la consolidación de los ya existentes, por lo que el IDA fue adquiriendo menos tierra y distribuyendo menos títulos (Guillén, 2015). La supuesta función social de formar propietarios rurales que dio origen al ITCO y posteriormente al IDA, se consideraba obsoleta frente a la perspectiva de desarrollo rural que motivó la reforma.

La Ley No. 9036 (2012) inaugura un gran cambio al establecer una serie de filtros institucionales, técnicos y legales que son creados dentro del mecanismo de dotación de tierras, el cual deja como última opción posible la obtención de un título de propiedad, pues el arrendamiento sería la forma principal de dotación de tierras. El establecimiento del INDER se basa en una profundización de los planteamientos del desarrollo rural hechos en los noventa por 
el IDA. Para entonces, el IDA definía este término así: "el mejoramiento continuo de la calidad de vida de la población gracias a la acción coordinada de instituciones y organizaciones vinculadas a la educación, la salud, el ambiente, el turismo y la infraestructura" (Picado y Silva, 2002, p. 149); según la nueva ley, el desarrollo rural territorial es el,

"proceso de cambio integral en materia económica, social, cultural e institucional, impulsado en un territorio rural, con la participación concertada y organizada de todos los actores sociales existentes en dicho territorio, orientado a la búsqueda de la competitividad, la equidad, el bienestar y la cohesión e identidad social de sus pobladores" (Ley No. 9036, art. 3, inc. i, 2012).

El carácter agrario que anteriormente daba sentido a la política pública ahora quedaba diluido en una versión de la nueva ruralidad con miras a la modernización de las actividades en el campo. Esto a través de la agroindustria, los servicios ambientales, el turismo y el comercio. De esta manera, se lleva a cabo desde una forma de gobernanza neoliberal, caracterizada por el ingreso de actores privados en el proceso de gobernanza, así como por la pre-eminencia del mercado como criterio de prioridad para la toma de decisiones.

A su vez, la Ley No. 9036 (2012) establece como su sujeto personas físicas y jurídicas sin fines de lucro que cumplan con los requisitos establecidos para convertirse en beneficiario. Estos sujetos están enmarcados por la definición del desarrollo rural territorial, que les dota de existencia social a partir de su imbricación en una red diversa de actores sociales descentralizados y responsables por la "búsqueda de la competitividad, la equidad, el bienestar y la cohesión e identidad social de sus pobladores" (art. 3, inc. i).

Para ser considerado "beneficiario", primero, hay que ser considerado con "idoneidad", las personas que buscan participar de la ley han de demostrar con estudios técnico su capacidad empresarial. Esta idoneidad se mantiene, solo si se comprueba la rentabilidad del "beneficio" obtenido, es decir, del arrendamiento. Lo que se hace evidente al mirar la historia agraria de Palmar Sur, es que, los sujetos que son el blanco de esta política desbordan los límites de la categoría "beneficiario". Las personas campesinas maniobran con esta categoría como una forma de asumir su condición de subordinación ante la mediación estatal, al mismo tiempo que buscan activar los recursos que la institución tiene con el fin de 
acercarse a la meta de concretar el acceso legal a las tierras.

Una vez el INDER define la idoneidad de las personas, se generan las condiciones para la segunda fase: la formulación de los proyectos productivos. La principal característica de los proyectos productivos es que tienen que demostrar la viabilidad económica del uso que la persona va a dar a la parcela. Este es uno de los marcadores neoliberales de la política, en primer lugar, es un filtro de acceso a un "beneficio" estatal, por lo que un lenguaje de derechos es inaplicable en esta política de marco, ya que, la tierra no es un derecho para los campesinos, sino un beneficio, cuyo acceso es escrutado por el estado a partir de criterios de mercado. Segundo, al estar este filtro determinado por la rentabilidad económica, el éxito se considera una responsabilidad individual.

En algún momento de este proceso de intervención, el INDER llegó a promover a las Fincas el cultivo de abacá como opción para formular los proyectos productivos. Los comités de tierra (luego convertidos en asociaciones de productores) se opusieron con una larga y legítima lista de razones: un gran riesgo de inversión que podría fracasar, dicho fracaso implicaría perder la tierra, al ser un cultivo extraño para la comunidad implicaría una curva de aprendizaje, que además conllevaría un aumento en los costos de producción y en el tiempo de retorno de la inversión. La última razón para la negativa fue que "el abacá no se come" por lo que en épocas difíciles no ofrece el respaldo que los campesinos tienen de productos que pueden usarse para el autoabastecimiento como los frijoles, el arroz, y el maíz. Por consiguiente, el INDER desistió de promover el abacá.

Este ejemplo de la negociación/oposición contra un proyecto productivo de abacá evidencia cómo las personas campesinas no se someten de manera total y pasiva a las exigencias estatales, aun cuando, muchas veces, en su rol de mediación con el estado los funcionarios hacen uso de amenazas (como desalojos o el revival del proyecto del aeropuerto internacional). Asimismo, las organizaciones tienen capacidad de negociación y maniobra con respecto al requisito de la rentabilidad, su negativa al abacá fue económica, cultural y política: el abacá no se come.

Por otra parte, la cantidad de requisitos y la presión de las autoridades para aprobar un proyecto productivo acorde con la ley también genera tensión y conflictos a lo interno de las organizaciones. 
La complejidad de los proyectos además de intimidar, y en algunos casos inhibir la participación en los mismos, requiere una cantidad de trabajo y conocimientos que en muchos casos sobrepasan las capacidades organizativas de las y los campesinos. Además de las partes típicas de un proyecto como título, resumen, antecedentes, justificación, objetivos y descripción, es necesario que el documento cuente con otras partes que requieren una serie de recursos técnicos y económicos que son de difícil acceso, incluso para el INDER. Estos son: estudio de gestión organizativa y administrativa, estudio técnico, estudio de mercado, estudio de requisitos legales, estudio ambiental, estudio económico financiero.

Si el proyecto productivo cumple con todos los requisitos, la Junta Directiva del INDER declara su idoneidad a partir de la evaluación y recomendación de las debidas dependencias internas, luego procede a identificar la modalidad de dotación que se implementará. La dotación es la forma genérica de denominar el proceso por el cual se obtiene la tierra en el sistema INDER, no quiere decir que se obtiene un título de tierra, sino que se puede ser sujeto de alguna de las dos modalidades de tenencia de tierras pertenecientes al INDER, a saber:

“El Inder dotará de tierras en la modalidad de arrendamiento, como forma prioritaria, en las fincas de su propiedad, para el desarrollo de proyectos productivos o de servicios de impacto comunitario en los territorios rurales, a título individual o en forma colectiva, ya sea como personas físicas o jurídicas" (Ley No. 9036, art. 50, 2012).

"En tierras propiedad del Inder podrán desarrollarse programas de asignación de tierras, bajo las modalidades individual y colectiva. La asignación individual se hará a la persona solicitante, a ambos cónyuges o convivientes en unión de hecho por igual, cuando esta relación exista. En la modalidad de asignación colectiva, a las organizaciones productivas o de servicios de los territorios rurales, la tierra será inscrita como propiedad social e indivisible. Las asignaciones respectivas estarán sujetas a la existencia de estudios técnicos que garanticen la idoneidad de los solicitantes, la cabida de las tierras, el proyecto productivo de la empresa o el servicio comunitario y su impacto para el desarrollo rural" (Ley No. 9036, art. 58, 2012).

Para que pueda mantenerse el derecho sobre el uso de la tierra, am- 
bas modalidades requieren el cumplimiento de ciertos criterios y requisitos. Además, están concatenadas en un proceso escalonado hacia la posible obtención de un título, esta etapa final requiere cumplir quince años bajo el estado de asignatario (Ley No. 9036, art. 66, 2012).

“Las formas de asignación deberán contar con un período de prueba, bajo la modalidad de contrato de arrendamiento, por un período de tres años como mínimo. Vencido el término del contrato de arrendamiento, los asignatarios que hayan satisfecho todas las obligaciones tendrán derecho a que se les otorgue título de propiedad, garantizando el pago de la tierra y de los créditos otorgados por el Inder con hipoteca sobre su tierra y la presentación de la respectiva póliza de deudor que respalde sus deudas" (Ley No. 9036, art. 62, 2012).

Por otra parte, las personas beneficiarias del INDER también pueden proponer proyectos no productivos, que, como su nombre indica no dependen de su rentabilidad. Estos proyectos proveen de servicios básicos a las comunidades en que se instalan, promoviendo el "desarrollo rural". Básicamente los proyectos no productivos, serían una de las formas de descentralización de la gobernanza neoliberal, pues actores sociales asumen tareas y roles antes asignados exclusivamente a entidades estatales, por medio de nuevas regulaciones que vuelven gobierno a un sujeto social. El siguiente gráfico resume y simplifica el proceso de dotación de tierras en el INDER:

En resumen, para el caso de Costa Rica el proceso de dotación implica, la declaratoria de intervención del INDER, la puesta en marcha de estudios de idoneidad de las personas físicas o jurídicas beneficiarias, la formulación y evaluación de proyectos productivos propuestos por esas personas, la declaratoria de idoneidad y la dotación de la tierra que contempla las modalidades de arrendamiento y adjudicación. Lo que la experiencia de la negociación estatal en Finca 10 parece mostrar es que, la titulación de tierras es una alternativa que queda por fuera de la mesa, ya que se ofrecen primordialmente arrendamientos cuya continuidad será determinada por la rentabilidad y sostenibilidad. 
Figura 1. Esquema del proceso de dotación de tierras en el INDER
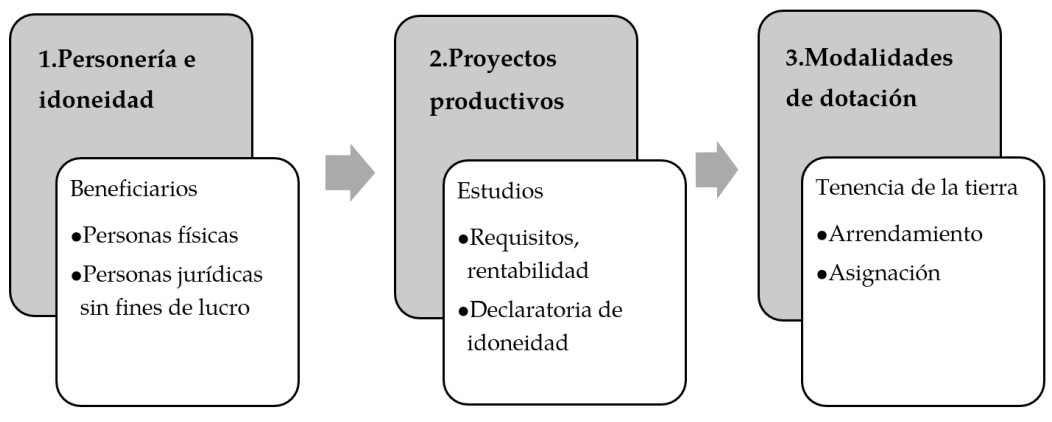

Fuente: Figura de elaboración propia con base en la Ley No. 9036 (2012).

Luego, la política de marco establecida en la ley INDER genera un cambio en las reglas del juego, donde la conducta de estos nuevos sujetos, lejanos al viejo prototipo del pobre sin tierra, es redirigida por la aspiración del desarrollo rural. En la incorporación de la propuesta del Banco Mundial y la nueva ruralidad dentro del discurso estatal, se pretende cubrir la osamenta campesina con el nuevo traje del emprendedor. Los objetivos primordiales del INDER están orientados de manera que

"crear una 'estructura de competencia' significa que la función del Estado no es ya proteger al ciudadano (...) sino crear las condiciones para que el ciudadano mismo se convierta en un actor económico (...). No hay transferencia de ingresos de unos a otros (distribución de la riqueza), sino estímulos laborales para que cada uno vea por sí mismo" (Castro-Gómez, 2015, pág. 187).

El sistema de distribución de tierras asumido por el INDER comparte con su esquema madre (las reformas agrarias orientadas por el mercado promovidas por el Banco Mundial en la década de 1990) dos de sus asunciones defectuosas. Por un lado, asume que la tierra es un factor económico en el sentido estricto, que debe asignarse para maximizar beneficios, dejando por fuera los tejidos sociales y significados culturales; por el otro lado, propone que en mercados 
que funcionan bien, la gente tiene condiciones de equidad y de voluntad para aceptar los precios de intercambio de las mercancías, intercambio que siempre es beneficioso (Akram-Lodhi, 2007). El prototipo de estas políticas no es la comunidad o la organización campesina, sino el individuo conducido por lo que la ley le exige, desempeñándose como emprendedor y demostrando, por medio de la competencia vigilada por el estado, que es capaz de producir como el beneficiario que institución modela. Los efectos de estas políticas son visibles en las formas de apropiación de actitudes y lenguajes relativos a estos prototipos, pero esta apropiación nunca es lineal o pasiva, ni necesariamente ocurre en las formas en que la política previene.

Estos procesos de formación estatal se dan en el encuentro con condiciones históricas concreta, visibles en las estructuras organizativas, sus legados históricos, sus resistencias internas y las transformaciones impuestas. En el caso de Chánguena por Siempre, la Junta Directiva estaba constituida por una mayoría de hombres; mientras que, la de Finca 10 por una mayoría de mujeres que quedaron sosteniendo los procesos de lucha por la tierra después de la coyuntura del aeropuerto. Después de todo, son justamente los liderazgos de mujeres los que han sostenido y operado las metas de las organizaciones. La forma en que ambas organizaciones estrategizan su relación con el estado es muy distinta y depende no solo de estas condiciones materiales, históricas y de género, sino también de la forma en la que la política pública codifica y reconduce sus prácticas productivas.

Después, en el 2017, el INDER decide intervenir ambos conflictos, tomando como base las organizaciones pre-existentes en las Fincas para moldearlas como asociaciones "idóneas" para participar en el nuevo proceso de repartición de tierras promovido con la reforma. El primer requerimiento de idoneidad es formar parte de una asociación legalmente constituida que formula y lleva a cabo el proyecto productivo con el formato que establece el INDER. Aunque el proyecto requiere de la colectividad de la asociación, la membresía a la misma depende de un proceso evaluación individual de los candidatos a miembros, dicha selección no es un proceso autónomo de la organización, sino mediado por la institución a través de entrevistas socio-económicas. La colectivización del proyecto productivo fue planteada para facilitar la eficiencia burocrática de la evaluación, pero terminó ralentizando y tensando 
procesos internos.

Ser una asociación legalmente constituida o, en palabras de las personas campesinas, "tener cédula jurídica" es uno de los requisitos primordiales para ser considerado potencial beneficiario; pero, es el INDER quien se responsabiliza de su constitución y registro a través de gestores de proyectos en oficinas regionales. Es también el INDER quién evalúa qué tan adecuada es su constitución, así como la aptitud de sus miembros - por medio de la unidad de proyectos de oficinas centrales-, así como la viabilidad, técnica, financiera, legal, y ambiental. Formar la asociación y luego evaluar qué tan idónea es resulta una de las características más esquizoides de esta política pública.

Chánguena por Siempre y Organización Lucha Campesina se han ido transformando al entrar en el proceso de registro como asociaciones de productores. El saber procedimental, el aumento en el protagonismo de las mujeres, los retrasos y ambigüedades institucionales en esa conformación han alimentado viejas tensiones y han creado algunas nuevas en la comunidad; especialmente, porque no todas las personas que están en las parcelas van a resultar beneficiadas con el arrendamiento. Resulta problemático que la búsqueda de idoneidad legal/administrativa afecte negativamente la organización, el aumento de tensiones dificulta la consecución del paso siguiente: la construcción colectiva de proyecto productivos y no productivos:
"Al INDER lo que le importa es que se haga el proyecto, diay, y yo calculo que cuando venga el momento de que nos toque plantear un proyecto comunal, ahí es donde va a estar el problema más serio, porque ahorita hay que reunirse sí o sí, ir a las reuniones y todo eso porque es un proyecto grande, de todos, pero cada quien está individual en su parcela, pero cuando tengamos que hacer el proyecto comunal, y no se puede quedar nadie solo haciendo un proyecto comunal, ahí es donde va a haber problemas y serios" (Señora G, comunicación personal, mayo, 2019).

Los tiempos de duración de los procedimientos son una grave preocupación. Finca 10 esperó dos años solo para tener en regla el requerimiento de la cédula jurídica. Aunque muchos debaten sobre las ventajas y desventajas del arrendamiento versus la titulación, lo cierto es que, los 5 años prorrogables de arrendamiento sumados a la prueba de 3 años para la asignación, y los 15 años de consoli- 
dación para optar por la compra para la titulación (Ley No. 9036, 2012) hacen virtualmente imposible el acceso a un título de propiedad, el título es una meta muy lejana para una población campesina envejecida. Según una encuesta realizada por el TCU 684, Cartografiando el conflicto Socioambiental, de la Universidad de Costa Rica, la edad promedio de las personas con parcela en Finca 9 era de 58 años, y de 55 años para Finca 10 y Finca Chánguena (2017).

\section{CONCLUSIONES}

La dinámica histórica de despojo de la tierra en Fincas debe entenderse como un proceso de acumulación primitiva, según la cual las y los productores son separados de los medios de producción a través de mecanismos extra-económicos para ser incorporados al mercado de trabajo y mercancías (De Angelis, 2000). La separación que ocurre en este caso es la del campesinado y la posibilidad real de tener tierra, pues la ley permite acceso solamente mediante el uso regulado (idoneidad) de este medio de producción. Asimismo, esta política pública responde a las definiciones foucaultianas de neoliberalismo (Foucault, 1979/2008), en la cual el rol del estado no es debilitarse o desaparecer, sino más bien, reconfigurar sus mecanismos de control para generar marcos de funcionamiento útiles a un mercado eficiente, el cual a su vez depende de subjetividades particulares moldeadas por dispositivos gubernamentales.

Es importante destacar que, esta separación facilitada por las políticas neoliberales no ocurre en un solo acto como un evento que de golpe desposee, sino que se basa en un proceso histórico continuo que permite al capitalismo desarrollarse (De Angelis, 2000; Akram-Lodhi, 2007; Ojeda, 2016). Elementos de la política pública como los plazos y periodos de prueba reproducen esta separación y terminan cimentando una relación de dependencia con la institucionalidad. Aunque esta nueva política de marco es de estilo neoliberal conserva elementos paternalistas de sus formas precedentes.

El despojo que opera en la separación de las personas productoras de los medios de producción nunca es absoluto. Durante el periodo bananero y de fracaso cooperativo, el despojo fue contestado con las tomas de tierras que se organizan en las Fincas. Estas contestaciones a su vez re-estructuran los procesos de dominación que buscan incorporarlas al desarrollo capitalista, en este caso, dicha incorporación opera a través del fomento del emprendedurismo, y el 
despliegue de un sistema de incentivos y presiones: si estas personas mantienen su subjetividad campesina, es posible que la tierra que han ocupado no sea incorporada al mercado mediante relaciones capitalistas, por lo que la integración de las y los productores y sus medios de producción es suplementada por la institucionalidad, ya que es "el estado que busca estructurar la asignación de recursos" (Akram-Lodhi, 2007, p. 1441).

Lo anterior se visibiliza de manera concreta con la importancia que el INDER da a la rentabilidad y la necesidad de mantener la tierra siempre como un valor económico. De no anteponerse a las presiones de este sistema emprendedurista, la tierra arrendada siempre puede ponerse a circular de nuevo en el mercado: el título es virtualmente imposible de acceder y el arrendamiento es relativamente fácil de perder. Es a través de estos mecanismos de control dentro de la política pública que se regulan las maneras en que las y los campesinos se convierten en emprendedores; en el momento en la institución pueda detectar descarrilamientos de estos mandatos, los "beneficiarios" corren el riesgo de perder el acceso a la tierra.

Además de contestado, el proceso no es lineal ni unívoco, generando diversidad de escenarios donde las y los campesinos hacen sus cálculos y negociaciones. Además de las diferencias y desacuerdos típicos de cualquier organización, la burocratización de los procesos generaba atrasos y prácticas internas que hacían que las personas campesinas se sintieran lejos de la meta principal de obtener la tierra, y la autonomía que valoraban como parte del ser campesino $^{7}$. Una parte de quienes ahora son beneficiarios del INDER vio en la tenencia de una parcela una grieta por la cual escapar a los mecanismos disciplinares del trabajo asalariado en el enclave bananero, e incluso del sistema cooperativo. Sin embargo, como se concluye arriba, la lógica estructurante de las relaciones capitalistas, en su imperativo de cooptación e incorporación, genera un estado de alerta o amenaza frente a la construcción de autonomías, por lo que estas suelen ser temporales y de estabilidad precaria. Mante-

7 Hablo de autonomía como esa búsqueda de no-dependencia, de libertad de decisión en lo que respecta no solo a la producción de la tierra, sino también de la cotidianidad y el modo de vida. Hablo de autonomía porque a mi parecer, es la palabra que mejor resume el espíritu con el que las personas campesinas con las que trabajé en Palmar Sur entienden su clase social y su papel político, aun cuando ellos y ellas poca o raras veces usan la palabra. 
ner esta autonomía implica una serie de negociaciones, en el que las maneras de ser y de nombrar entran en juego, pues defender la tierra ha implicado que las y los campesinos se pongan el sombrero de "beneficiario" del INDER y el traje de "emprendedor"8 en la formulación de proyectos productivos y desde ahí establecer un lugar de enunciación para articular demandas que continúan teniendo un sentido campesino, como ocurrió con la oposición al cultivo de abacá.

Las formas de acción colectiva, en Finca 10, habitaron lo que De Angelis (2007) llamaría el reino de lo invisible, pues se transformaron poco a poco en un objeto de intervención para el INDER. En la búsqueda de regularización o formalización, la intervención no transcurrió solo como un cambio en el estatus legal de las tierras y sus poseedores, ya que venía acompañada de un proceso más amplio de control económico y político del trabajo y la producción.

Comprender las dimensiones neoliberales de la política del INDER es de suma importancia, ya que, "la manera en que se tiene la tierra afecta la capacidad del capital para transformar la agricultura" (Akram-Lodhi, 2007, p. 1442). Si se observan las fases tempranas de la neoliberalización del sector primario en Costa Rica durante la transformación del ITCO en el IDA, la titulación era plausible para personas que fueran parte de los programas de parcelación o de las intervenciones estatales en ocupaciones precarias. En la fase siguiente se puede identificar la consolidación del INDER, cuyas reformas afectan negativamente el derecho de propiedad de la tierra para los "beneficiarios" de la política social. La formal y temporalmente lejana posibilidad de obtener un título de propiedad implica que la parcela ya no es un respaldo ante el riesgo de tener que enfrentar tiempos difíciles, por medio de una venta o hipoteca. Sin título, la tierra deja de ser una garantía o forma de amortiguación de la pobreza, también quedaban descartados los limitados márgenes de maniobra de administración autónoma de la parcela. La tenencia de la tierra en esta segunda fase está condicionada a un modelo de agricultura emprendedurista, basado en la rentabilidad, en un contexto nacional y global de hegemonía del monocultivo.

Es así que, la promesa fallida de la tierra durante el fomento cooperativo y el espejismo de la titulación de parcelas en el modelo

8Que, como en el cuento "El Traje Nuevo del Emperador" (1837), constituía solo una ilusión cuya materialidad denotaba otra realidad. 
neoliberal de repartición son parte de un proceso complejo de desposesión. Después de que se "fue" la Compañía Bananera, de que emigraron los desempleados, de que se arrancaron los rieles del ferrocarril, y de que las cooperativas que el estado hizo nacer en la quiebra cerraran, quedaron muchas personas trabajando las tierras y sosteniendo la comunidad, pero "la gente se nos hizo vieja, se nos está muriendo la gente y es un pecado" (Señor M, comunicación personal, 12 octubre, 2018).

\section{FUENTES CONSULTADAS}

Akram-Lodhi, A. H. (2007). Land, Markets and Neoliberal Enclosure: An Agrarian Political Economy Perspective. Third World Quarterly, 28 (8), 1437-1456. https://doi.org/10.1080/01436590701637326

Benavides, G. (2019). Informe de verificación de derechos humanos. La indigna situación de familias que viven dentro de las haciendas de abacá de la empresa japonesa Furukawa Plantaciones C.A del Ecuador. Defensoría del Pueblo de Ecuador.

Cartín, S., y Román, I. (1991). Echando raíces. La lucha por la tierra en Costa Rica. Documento de análisis $N^{\circ} 17$. Centro de Estudios para la Acción Social.

Castro-Gómez, S. (2015). Historia de la Gubernamentalidad I. Razón de Estado, liberalismo y neoliberalismo en Michel Foucault. Siglo del Hombre Editores.

Clare, P. (2011). Los cambios en la cadena de producción de la palma aceitera en el Pacífico costarricense. Una historia económica, socioambiental y tecnocientífica 1950-2007. Sociedad Editora Alquimia 2000 S.A.

De Angelis, M. (2000). Marx's Theory of Primitive Accumulation: A Suggested Reinterpretation ( Working Paper No. 29). University of East London, Department of Economics. Disponible en: https://citeseerx. ist.psu.edu/viewdoc/download?doi=10.1.1.200.9435\&rep=rep1\&type $=$ pdf

De Angelis, M. (2005). The Political Economy of Global Neoliberal Governance. Fernand Braudel Center, 28 (3), 229-257.

De Angelis, M. (2007). The Beginning of History. Value Struggles and Global Capital. London and Ann Arbor: Pluto Press.

Deininger, K. (2003). Land Policies for Growth and Poverty Reduction. A World Bank Policy Research Report. World Bank and Oxford University 
Press. Disponible en: http://hdl.handle.net/10986/15125

Díaz Arias, D. (2019). Historia del Neoliberalismo en Costa Rica. La aparición en la contienda electoral 1977-1978. Centro de Investigaciones Históricas de América Central. Disponible en: https://cihac.fcs.ucr.ac.cr/ wp-content/uploads/2019/08/David-Diaz-Historia-del-Neoliberalismo-CIHAC.pdf

Domínguez, R., Domínguez, M., Vargas, A., Artavia, F., Chavarría, J., Chavarría, J., Hidalgo, S., Jiménez, B., Tencio, J. Vargas, H., Vargas, G., Cortés, S., Guadamuz, E., Hernández, C., Maroto, J., Morales, E., Murillo, J., Murillo, J., Quintero, C. (2019). Tierras en lucha, resistencia campesina. Atlas de la memoria de las comunidades de Finca Chánguena, Finca 9 y Finca 10 de Palmar Sur de Osa, 2016-2019. Universidad de Costa Rica.

Ferlini, A. (11 de Junio, 2012). Botas con Machete - No al Aeropuerto Internacional del Sur [video]. Disponible en: https://cutt.ly/Bhe5YGr

Fernández, M. (2004). La agricultura costarricense ante la globalización. Las nuevas reglas del comercio internacional y su impacto en el agro. Editorial de la Universidad de Costa Rica.

Foucault, M. (2008). The Birth of Biopolitics. Lectures at the Collège de France (1978-1979). Palgrave Mcmillan.

Foucault, M. (2009). Security, Territory, Population. Lectures at the Collège de France (1977-1978). Palgrave Mcmillan.

Foucault, M. (2011). The government of the self and others. Lectures at the Collège de France (1982-1983). Pagrave Mcmillan.

Guillén, M. J. (2015). Estado, enclave y campesinado. Conflicto agrario en Río Frío de Sarapiquí, 1980-2009 [Tesis de licenciatura en Ciencias Políticas, Universidad de Costa Rica]. Disponible en: http://hdl.handle. net $/ 10669 / 29940$

Guillén, M. J. (2018). Al compás de la tonada estatal: conflicto agrario en Sarapiqui 1980-2009. Revista Reflexiones 97(1), 27-38. DOI 10.15517/ RR.V9711.31279

Harvey, D. (2008). El neoliberalismo como destrucción creativa. Revista Apuntes del CENES, 27(45), 10-34. Disponible en: https://revistas. uptc.edu.co/index.php/cenes/article/view/3032

INEC. (2015). VI Censo Nacional Agropecuario. Resultados generales. Instituto Nacional de Estadística y Censos. Disponible en: http:/ / www.mag. go.cr/bibliotecavirtual/U40-10581.pdf

Kay, C. (2006). Rural poverty and development strategies in Latin American. Journal of Agrarian Change, 6(4), 455-508. https://doi.org/10.1111/ 
j.1471-0366.2006.00132.x

Kay, C. (2007). Algunas reflexiones sobre los estudios rurales en América Latina. ICONOS Revista de Ciencias Sociales (29), 31-50. https://doi. org/10.17141/iconos.29.2007.230

Kay, C. (2015). The agrarian question and the neoliberal rural transformation in Latin America. European Review of Latin American and Carribean Studies, (100), 73-83. http://www.jstor.org/stable/43673539

Lahiff, E., Borras, S., y Kay, C. (2007). Market-Led Agrarian Reform: Policies, Performances and Prospects. Third World Quarterly, 28(8), 14171436. https://doi.org/10.1080/01436590701637318

Llaguno, J. J., y Picado, H. (19 de julio, 2011). Costa Rica: Legalizar el despojo de la tierra. Grain. https://cutt.ly/Hhe6dpr

Martínez, G., y Morales, M. P. (2012). El Instituto de Desarrollo Agrario y los procesos organizativos de las mujeres rurales. Caso de los grupos de mujeres de Florida y Louisiana de Siquirres (1990-2006) [Tesis de licenciatura en Ciencias Políticas, Universidad de Costa Rica].

Mezzadra, S. (2014). La cocina de Marx. El sujeto y su producción. Buenos Aires: Tinta Limón.

Mora, S. (2007). Costa Rica en la década de 1980: estrategias de negociación política en tiempos de crisis ¿Qué pasó después de la protesta? Inter.c.a.mbio, 4 (5), 165-183. Disponible en: https://revistas.ucr.ac.cr/ index.php/intercambio/article/view/3800

Morales, N., y Segura, R. (2017). Distribución de la tierra y su relación con la desigualdad social. En INEC, Una visión del sector agropecuario basada en el CENAGRO 2014 (p.p. 209-229). Instituto Nacional de Estadística y Censos.

Ojeda, D. (2016). Los paisajes del despojo: propuestas para un análisis desde las reconfiguraciones espaciales. Revista Colombiana de Antropología, 52(2), 19-43. Disponible en: https://www.redalyc.org/ pdf/1050/105049120002.pdf

Partido Liberación Nacional. (1981). Volvamos a la Tierra. Programa de Gobierno 1982-1986. Editorial Artes Gráficas. Disponible en: http:/ /www. asamblea.go.cr/sd/Partidos\%20Polticos $\% 20$ Programas $\% 20$ de $\% 20$ Gobierno/Programa\%20de\%20Gobierno\%20PLN\%201982-1986\%20 L\%20Monge\%20Volvamos\%20a\%20la\%20Tierra.pdf

Picado, W., y Silva, M. (2002). De la colonización al desarrollo rural. IDA. Cuarenta años de paz social en Costa Rica 1961-2001. Instituto de Desarrollo Agrario. 
Pomareda, F. (11 de julio, 2016). Finca Chánguena: el triunfo legal no repara todo el daño causado. Informa-Tico. https://cutt.ly/0he6bWF

República de Costa Rica. (2012). Ley No 9036 Transformación del Instituto De Desarrollo Agrario (IDA) en el Instituto De Desarrollo Rural (INDER).

TCU 684. (2017). Informe de encuesta. Situación socioeconómica en Palmar Sur, Finca 9, Finca 10 y Finca Chánguena 2017. Universidad de Costa Rica.

Vega, L. (30 de noviembre, 1984). Psicosis ante retiro de la bananera. La Nación, pág. 4A.

Vela, C. (2018). Capitalismo terminal. Anotaciones a la Sociedad Implosiva. Traficantes de Sueños.

Wiley, J. (2008). The banana empires, trade wars and globalization. Lincoln and London: University of Nebraska Press.

MARÍA JOSÉ GUILLÉN ARAYA es costarricense. Licenciada en Ciencias Políticas por la Universidad de Costa Rica. Estudiante de Doctorado en Geografía en Clark University, Worcester, Massachussets, Estados Unidos. 